\title{
СОПОСТАВИТЕЛЬНЫЙ АНАЛИЗ РУССКОГО И АРАБСКОГО ГЛАГОЛА В УЧЕБНЫХ ЦЕЛЯХ (КАТЕГОРИЯ ВИДА И ВРЕМЕНИ)
}

\section{COMPARATIVE ANALYSIS \\ OF THE RUSSIAN AND ARABIC VERB FOR EDUCATIONAL PURPOSES (TYPE AND TIME CATEGORY)}

\section{O. Gadzhimirzoeva}

Summary: The article examines the categories of verb type and tense in the Russian and Arabic languages. The significant differences that exist in the investigated categories in both Arabic and Russian grammatical forms, cause significant difficulties with learning Russian language. The material of the comparative analysis allows to organize more effectively work on formation of speech skills of students, to carry out the analysis of errors, to prevent their occurrence.

Keywords: perfect, imperfect, categories of type and time, verb, comparison.

\author{
Гаджимирзоева Олеся Сабировна \\ К.филол.н., дочент, ФГБОУ ВО «Дагестанский \\ государственный университет» \\ olesya_sab@mail.ru
}

Аннотация: В статье исследуются категории вида и времени глагола в русском и арабском языках. Существенные различия, существующие в исследуемых категориях в арабской и русской грамматических формах, вызывают значительные трудности при обучении русскому языку. Материал сопоставительного анализа позволяет более эффективно организовать работу по формированию речевых навыков студентов-иностранцев, провести анализ ошибок, предупредить их появление.

Ключевые слова: перфект, имперфект, категории вида и времени, глагол, сопоставление.

но важной и специфичной [4, с. 42].

Исследованию категорий времени и вида в русском языке посвящено много работ (так, глубокую трактовку этих категорий находим, например, у А.В. Бондарко и Ю.С. Маслова). Невозможно в небольшой статье учесть все семантические и функциональные особенности указанных категорий, поэтому мы коснемся лишь некоторых моментов, которые помогут понять сущность грамматической интерференции в речи студентов-арабов, изучающих русский язык.

Приведем несколько примеров употребления арабских глагольных форм. Так, например, передавая содержание книги или статьи, носитель русского языка использует формы настоящего времени: «В книге автор рассматривает ..., изображает ..., описывает ...». Для носителя арабского языка в данном случае естественны формы прошедшего времени глагола: Автор рассмотрел ...» изображал ..., описывал. Арабское языковое сознание представляет действие как свершившееся, законченное, отнесенное в прошлое. Когда мы видим приближающийся к перрону поезд, мы скажем: «Поезд прибывает». Для носителя арабского языка естественно сказать: «Поезд прибыл». Приведем еще пример. Пословица «Кто ищет, тот найдет» существует также и в арабском языке, но характерно то, что в арабском языке для передачи этого значения попользуются формы прошедшего времени 
«Кто приложил усилия, тот нашёл». Таким образом, в работе над формами настоящего времени в русском языке следует обращать внимание студентов на все возможные случаи употребления этих форм в русском языке.

В арабском языке морфологически противопоставлены две глагольные формы, причем семантика этого противопоставления в гораздо большей степени определяется аспектуальными, а не временными факторами [2, с.132]. Для разных групп глаголов оказывается более существенным либо видовой фактор, либо временной. Как правило, временные факторы бывают более существенными для глаголов действия, а не для глаголов состояния. В лингвистической литературе две противопоставленные формы арабского глагола принято обозначать как перфект и имперфект [1, с.146]. Перфект обозначает в основном завершенное, законченное действие, а имперфект - действие незавершенное, продолжающееся, развертывающееся или предстоящее. Поэтому естественным является соотнесение первой из этих форм преимущественно с планом прошедшего времени, а второй - с настоящим или будущим временем. Однако следует отметить, что, если перфект может передавать различные времена, но все же чаще всего прошедшее, то диапазон имперфекта шире, им можно обозначать действие, отнесенное к любому времени, лишь бы это действие мыслилось как незавершенное. Б.М. Гранде в связи с этим пишет, что в конкретных случаях действие, выраженное глаголом в форме имперфекта, всегда относится к какому-либо одному определённому времени, тем не менее, в его употреблении ни одно из этих времён не имеет преимущества и, таким образом, «арабские так называемые времена глагола сами по себе, без определённого «окружения» во фразе, не могут уточнить время действия» $[1$, с. 159].

Употребление арабами русских форм настоящего времени в некоторых случаях в значении прошедшего времени является одной из наиболее распространенных ошибок.

Отметим также, что арабский язык располагает целым рядом средств, помимо морфологии спрягаемого глагола, для точного указания времени действия в случае такой необходимости. Так, например, используются особые частицы перед глаголом в форме имперфекта (так называемого настоящего времени): частица «сауфа» четко указывает на временной план будущего, частица «лян» перед формой имперфекта имеет значение категорического отрицания действия.

Арабский язык располагает достаточными средствами для выражения временных отношений, но в системе арабских спрягаемых глагольных форм и соотношение видовых и временных факторов в рамках этой системы существенно отличаются от видовременной системы русского глагола. Исходя из тех замечаний, которые были сделаны выше, предложим некоторые конкретные пути использования данных сопоставительного анализа русского и арабского глаголов в процессе обучения русскому языку.

Морфологическая категория времени в русском языке - это системное противопоставление друг другу рядов форм, обозначающих отношение действия ко времени его осуществления» [5, с.626]. В арабском языке глагольные формы не соотнесены с реальным временным планом и членение их осуществляется по другому принципу - выделяется действие законченное и действие разворачивающееся, продолжительное, поэтому в работе над категорией времени необходимо постоянно подчеркивать связь формы в русском языке с определенным временным планом. Формы настоящего времени должны быть противопоставлены формам прошедшего и будущего времени. Реальный временной план можно подчеркнуть словом «эль-хаг-», которое обозначает настоящий момент, связь с временным планом прошлого заключена в слове «эль-мады», слово «эль-мустакабаль» выделяет реальный план будущего. Особое внимание следует обращать на правильное использование форм будущего времени в русском языке, так как в арабском языке будущее время тесно связано с настоящим [3, с.182].

Здесь важно указать на то, что в русском языке ближайшее к настоящему времени действие требует употребления формы будущего времени, а не настоящего, как в арабском языке. Часто встречаются такие ошибки. На вопрос преподавателя: «Почему опоздали?» студент отвечает; «Сейчас я вам говорю». Или: «Почему нет журнала?»- «Сейчас иду и беру». Свободное функционирование форм имперфекта (или форм так называемого настоящего времени) в плане прошедшего времени объясняет ошибки типа: «Сел за стол и пишу письмо, прочитал и говорю» и т.п. В арабском языке достаточно употребить только первый глагол. В предложении в форме прошедшего времени, чтобы и все последующие действия, выраженные формой имперфекта, воспринимались в плане прошедшего времени. В данном случае работа над категорией времени переходит в работу над категорией вида русского глагола. Форма так называемого прошедшего времени (перфекта) может быть переведена на русский язык, как формой глагола несовершенного вида, так и формой глагола совершенного вида в зависимости от контекста. Только глаголы чувственного восприятия, мыслительной деятельности и т.п. в форме перфекта соответствуют глаголам совершенного вида в русском языке и могут быть переведены, например, узнал, полюбил, понял, почувствовал и т.п. В случае, когда необходимо подчеркнуть продолжительность действия в прошлом, в арабском языке используется аналитическая форма: глагол в форме имперфекта (настоящего 
времени) в сочетании с глаголом «быть» в форме прошедшего времени (кава). Значения же глаголов совершенного вида могут быть обнаружены у форм арабского перфекта при помощи соответствующих синтаксических и лексических средств в предложении и в контексте.

Категория вида в русском языке - это «система противопоставленных друг другу рядов форм глаголов, обозначающих ограниченное пределом целостное действие (глаголы совершенного вида) и ряда форм глаголов, не обладающих признаками ограниченного пределом целостного действия (глаголы несовершенного вида)» [5, c.583]. Таким образом, определяющим моментом в форме русского глагола совершенного вида является ограничение действия пределом в отличие от представления действия как процесса в его длительности и повторяемости. Представления о действии завершенном (фи'ель муктамаль) и о действии как процессе, о действии, продолжающемся или повторяющемся (фи'аль хейр муктамаль), которые существуют в арабском языковом сознании, должны быть скорректированы в соответствии с особенностями употребления видов в русском языке.

При работе над формами прошедшего времени глаголов несовершенного вида следует сопоставлять их с формами настоящего времени: сейчас он пишет упражнение - вчера он писал упражнение.

Необходимо подчеркнуть характер процесса в данном действии. Формы нестоящего времени в русском и арабском языках представляют действие как процесс. То есть следует показать, что функция глаголов несовершенного вида в форме прошедшего времени такая же, как и у форм настоящего времени, но действие отнесено в прошлое. Длительность можно подчеркнуть лексическими средствами. Добивать правильных речевых действий можно путем сопоставления общефактического значения несовершенного вида и значения длительности действия, например:

- Что ты делал вчера? - Читал. - Долго? - 2 часа.

- Ты переводил вчера статью? - Переводил. - Сколько времени?

- Весь вечер и т.п.

Следует предупреждать появление ошибок такого рода, как: он был читает или он был читать, она была говорит, которые являются буквальным переводом с арабского языка. В данном случае глагол «был» является вспомогательным в арабском языке и указывает на время действия, а основной глагол обозначает характер протекания действия. При работе над этими ошибками следует добиваться понимания того, что в русском языка в одной глагольной форме заключено значение вида и времени и использование других средств для выражения этого значения избыточно.
В арабском языке отмечают существование таких контекстов, в которых формы перфекта и имперфекта в плане прошедшего времени могут быть противопоставлены как характеризующие действия, однократные и повторяющиеся действия [6, с.405]. Употребление русских глаголов в тех же значениях обычно не вызывает затруднений у студентов.

В учебниках русского языка обычно выделяются такие значения совершенного и несовершенного видов, как значение последовательности и одновременности действий. Эти значения не имеют четкого грамматического оформления в арабском языке. Данные значения могут выражаться при помощи одного и того же глагола и, наоборот, одно значение выражается разными глаголами. Академическая грамматика русского языка, отмечая значение последовательности фактов как значения совершенного вида, указывает при этом на завершенность каждого действия. Рассматривая различные значения глаголов совершенного и несовершенного видов, Р.А. Этова обращает внимание на то, что «при изучении основных значений несовершенного и совершенного видов представляется необходимым уже на начальном этапе вводить понятие границы действия, противопоставляя это значение совершенного вида значению процесса, продолжительности действия для глаголов несовершенного вида» [7, с.25]. Поэтому в работе над значением последовательности фактов необходимо, прежде всего, подчеркнуть момент «ограничения одного действия другим действием». Самые распространенные ошибки в употреблении видов в этом случае следующие: «он вошел и видел; привел и рассказывал». Такое употребление глагольных форм отражает особенности функционирования арабского перфекта и имперфекта. В данном случае мы наблюдаем не различение значений совершенного и несовершенного видов. Правильные речевые действия нужно начинать отрабатывать на глаголах, имеющих значение краткого действия: прочитал и дал; написал письмо и закрыл конверт. Следует обратить внимание студентов на элемент динамики, свойственный глаголам совершенного вида: «Присущее совершенному виду значение ограниченного пределом целостного действия отделяет, отграничивает одно действие от другого: сначала достигает предела своего совершения один факт, затем наступает второй, третий...» [5, с.605]. В арабском языке для выражения действия, которое закончилось до наступления второго, есть особая форма, которая используется, когда это значение необходимо подчеркнуть, это так называемое преждепрошедшее: «был уже писал». Чтобы предупредить появление ошибок типа: он был писал и сказал; он был прочитал книгу и дал ее, следует постоянно обращать внимание студентов на то, что в русском языке значение завершенности действия до начала другого действия заключено в самой глагольной основе. Для арабского языкового создания подобные значения выражаются аналитически, этим 
объясняется частое избыточное употребление в русской речи арабов глагола «быть» наряду с основными глаголами. В работе над видами глагола в форме инфинитива нужно иметь ввиду, что в арабском языке неопределенная форма глагола отсутствует и инфинитив в русском языке соответствует личной форме глагола в арабском языке, например: начал читать (русский язык) начал читает (арабский язык); продолжаю читать (русский язык) продолжаю читаю (арабский язык).

Употребление инфинитива совершенного и несовершенного вида у глаголов, допускающих оба варианта, должно быть рассмотрено отдельно в каждом конкретном случае. Так, например, различия значения словосочетаний: хочу читать и хочу прочитать - можно объяснить лишь описательно, так как в арабском языке эти значения не различаются, и двум словосочетаниям в русском будет соответствовать одно в арабском: хочу читать.

Сопоставим два предложения: «Эти студенты хотят быстро изучить русский язык». - «Эти студенты хотят изучать русский язык». В арабском языке смысловое различие между этими предложениями может быть выражено на лексическом уровне - лексический состав предложений будет различен: «Эти студенты хотят изучать русский язык». - «Эти студенты хотят знать русский язык».

Особенности значения совершенного и несовер- шенного видов глагола можно пояснить, сопоставляя различное лексическое оформление фраз, имеющих синонимичное значение: «хочу изучать = хочу заниматься языком; хочу изучить = хочу знать, владеть» и т.п.

При работе над видовыми различиями инфинитивов необходимо подчеркивать связь грамматической формы и значения в русском языке. Значение глагольных словосочетаний: «обещаю писать - обещаю написать; можно звонить - можно позвонить» и т.п. не различаются в арабском языке, поэтому в упражнениях следует наглядно показать связь семантики с грамматической формой: «обещаю писать всегда - обещаю написать завтра; можно иногда звонить вам? - можно позвонить вам в 3 часа?; старому человеку нужно помогать - вашему товарищу нужно помочь подготовиться к контрольной работе» и т.д. Наглядные примеры тесного взаимодействия значении и формы в русском языке проявляются в следующих словосочетаниях: «хотим поздравить (с конкретным праздником) - любим поздравлять (всегда, обычно)». В арабском языке эти значения нерелевантные и грамматически не выражены, используется в том и другом значении одна форма имперфекта: «хотим, поздравляем» и «любим поздравляем».

Материал сопоставительного анализа позволяет более эффективно организовать работу по формированию речевых навыков студентов, провести анализ ошибок, предупредить их появление.

\section{ЛИТЕРАТУРА}

1. Гранде В.М. Курс арабской грамматики в сравнительно-историческом освещении / Рос. акад. наук. Ин-т востоковедения, Моск. гос. ун-т им. М.В. Ломоносова. - 2. изд. - М.: Изд. фирма «Вост. лит.» РАН, 2001. - 592 с.

2. Дьяконов И.М. Семитско-хамитские языки. - М., 1965. - 119 с.

3. Ковалев А.А., Шарбатов Г. Учебник арабского языка.- Изд. 3-е, исправленное и дополненное. -М.: Издательская фирма «Восточная литература» РАН, 1998.- $751 \mathrm{C}$.

4. Маслов Г.С. К основаниям сопоставительной аспектологии // Вопросы сопоставительной аспектологии. Л, 1978. - 195 с.

5. Русская грамматика / Н.Ю. Шведова (гл. ред.). - М.: Наука, 1980. - Т. 1: Фонетика. Фонология. Ударение. Интонация. Словообразование. Морфология. $789 \mathrm{c}$.

6. Шагаль В.Э., Мерекин М.Н., Забиров Ф.С. Учебник арабского языка. Издательство: Военное издательство, - 1983 год, - 784 с.

7. Этова Р.А. Сопоставительный анализ грамматических систем русского и арабского языков [Текст]: Глагол: (Метод. рекомендации для слушателей ФПК). М., Ун-т дружбы народов, 1979. - 59 с.

8. Ярцева В.Н. Контрастивная грамматика - М., Наука, 1981. - 112 с.

(с Гаджимирзоева Олеся Сабировна (olesya_sab@mail.ru). Журнал «Современная наука: актуальные проблемы теории и практики» 